\title{
FEM investigation of concrete silos damaged and reinforced externally with CFRP
}

Sihem Kermiche ${ }^{1,2, *}$, Ouzine Boussaid ${ }^{3}$, Bachir Redjel $^{4}$, and Abdelaziz Amirat ${ }^{5}$

\author{
${ }^{1}$ Assistant Professor, Civil Engineering Laboratory, Badji Mokhtar University, PO Box 12, 23000 Annaba, Algeria \\ ${ }^{2}$ Mohamed Cherif Messaadia University, PO Box 1553, Annaba Road, 41000 Souk-Ahras, Algeria \\ ${ }^{3}$ Senior Lecturer, Research Laboratory on Industrial Risks, Control and Safety, Badji Mokhtar University, \\ PO Box 12, 23000 Annaba, Algeria \\ ${ }^{4}$ Professor, Civil Engineering Laboratory, Badji Mokhtar University, PO Box 12, 23000 Annaba, Algeria \\ ${ }^{5}$ Professor, Research Laboratory of Advanced Technologies in Mechanical Production, Badji Mokhtar University, \\ PO Box 12, 23000 Annaba, Algeria
}

Received: 28 July 2017 / Accepted: 9 October 2017

\begin{abstract}
The present work investigates the reinforcement of concrete wheat-grain silos under initial damage. The reinforcement is achieved by mounting bands of carbon fiber reinforced polymer (CFRP) on the external walls of the silo. 4 modes of reinforcement are adapted according to the width of the band, the gap between two bands, the height of reinforcement and the number of layers achieved through banding. Analytical analyses were conducted using the Reimbert method and the Eurocode 1 Part 4 method, as well as numerically through the finite element software Abaqus. Results show that the normal pressure reaches a peak value when approaching the silo hopper. Initial damage in a concrete silo was first determined using a 3D geometrical model, while the damage analyses were conducted to optimize the CFRP reinforcement by mounting 2 CFRP bands close together above and below the cylinder-hopper joint. Increasing the number of banding layers could produce better performance as the damage was slightly decreased from 0.161 to 0.152 for 1 and 4 layers respectively.
\end{abstract}

Keywords: Concrete silos / damage / external reinforcement / CFRP / FEM

\section{Introduction}

Reinforced concrete silos (CSs), which are commonly used for the storage of granular or powdery materials (e.g. cereals and cement), are structures subjected to temperature variations and stresses when being filled and emptied. These actions usually generate global or localized vertical cracks in the structure walls, which leads to a shorter lifetime $[1,2]$. The cracks are usually observed to one-third the height of the silo [3]. This phenomenon has appeared on wheat silos build in the 1960s and in the 1980s [3,4]. Crack reparation is commonly achieved through the usual techniques such as grout or concrete injection. However, these techniques are not efficient at stopping the propagation of cracks [5]; therefore, there is a great need to find new and reliable solutions.

Reinforcement of the structure through external wall bonding using carbon fiber reinforced polymers (CFRPs) is a new technique that is currently well adopted. Meanwhile, most of research in the literature regards the reinforcement

\footnotetext{
* e-mail: kersihe18@gmail.com
}

of cracked beams using CFRP, but CFRP reinforced silos still require additional investigations. Most of these investigations studied the behavior of various parameters on silos, such as the effect of boundary conditions [6,7], the effect of grain-flow regimes [8] and the material properties $[9,10]$. Also, the interactions between the structure of a silo and its stored material is of great interest [11-13].

Pressure prediction has been carried out through theoretical and experimental investigations on silo walls under static and dynamic loading, where adequate solutions were found. Elghazouli and Rotter [14] have shown that inadequate control of cracks causes rapid deterioration of strength and may often lead to the premature failure of the structure. Even the construction method has a significant influence on the structural behaviour and may substantially increase the vulnerability of a structure. Nateghi and Yakhchalian [15] have studied the effect of the granular material-structure interaction for reinforced CS during seismic behaviour. They reported that when the effective mass of granular material is equal to $80 \%$ of the total granular material mass, then more severe tension damage occurs in silo walls. Ezz El-Arab [16] observed the flow pattern and wall pressures during the 


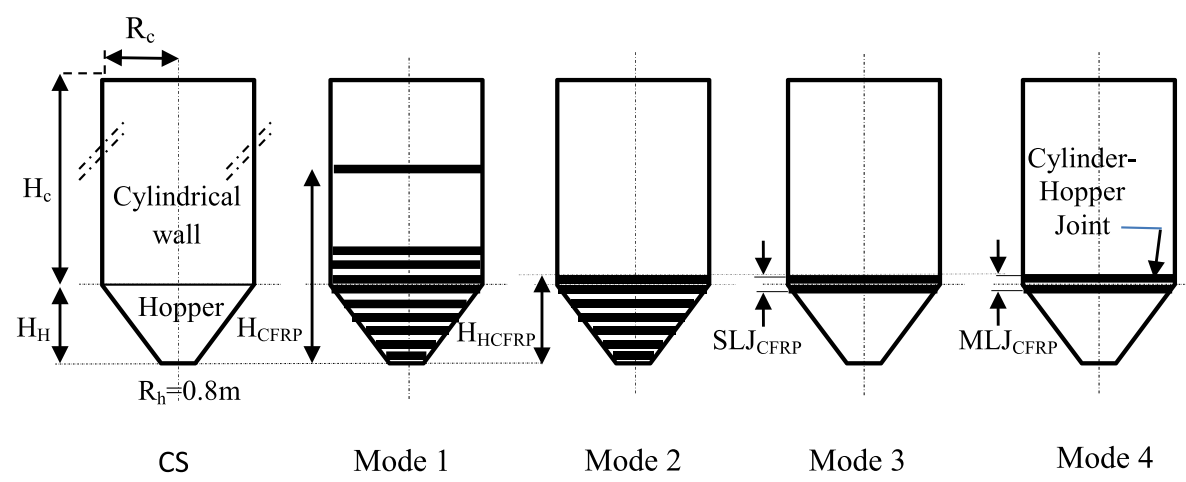

Fig. 1. Concrete silo (CS) and modes of CFRP reinforcement in silos.

Table 1. Geometrical characteristics in CFRP concrete silos.

\begin{tabular}{llllllllll}
\hline $\begin{array}{l}\text { Total } \\
\text { height } \\
(\mathrm{m})\end{array}$ & $\begin{array}{l}\text { Cylinder } \\
\text { height, } \\
H_{c}(\mathrm{~m})\end{array}$ & $\begin{array}{l}\text { Cylinder } \\
\text { radius, } \\
R_{c}(\mathrm{~m})\end{array}$ & $\begin{array}{l}\text { Hopper } \\
\text { height, } \\
H_{H}(\mathrm{~m})\end{array}$ & $\begin{array}{l}\text { Hopper } \\
\text { hatch } \\
\text { radius, } \\
R_{h}(\mathrm{~m})\end{array}$ & $\begin{array}{l}\text { Wall } \\
\text { thickness, } \\
T_{w}(\mathrm{~m})\end{array}$ & $\begin{array}{l}\text { CFRP total } \\
\text { height, } \\
H_{\text {CFRP }}\end{array}$ & $\begin{array}{l}\text { CFRP hopper } \\
\text { height, } \\
H_{\text {HCFRP }}\end{array}$ & SLJ $_{\text {CFRP }}$ & MLJ JFRP \\
\hline 30 & 27 & 3 & 3 & 0.8 & 0.18 & $(1 / 3) \mathrm{H}$ & 3.3 & $2 \times 0.3$ & $2 \times 0.3$ \\
\hline
\end{tabular}

filling and emptying of cylindrical reinforced CS under three seismic excitations. Numerical and experimental static and dynamic analyses showed that the results were in good agreement.

Investigations of CS repaired after crack degradation are very limited. Yonggang et al. [3] used numerical simulations to analyse the performance of silos after strengthening their structures with CFRP laminates, but they did not include the wall-stored material in their analysis. The behaviour of concrete is considered to be elastic. There have been $63 \%$ decrease in the first principal stresses, while the values of the third principal stresses were not significantly lower. This suggests that the use of CFRP can restrain the advent and expansion of cracks. The work reported by Louetri et al. [17] enhances the interest of using CFRP in silos. They have presented a numerical analysis of the reinforcement of steel slender silos having concentric hopper with CFRP. In their simulations, the influence of different reinforcement layers and the placement of reinforcement have been analyzed to show that up to $50 \%$ reduction of stresses were obtained in the silo with five layers compared to a silo with non-reinforced wall. They suggested that the reinforcement with CFRP could be of interest for silos having suffered from damage and alterations that induced a reduction in the thickness of their walls.

The present work is an investigation on the reinforcement of a concrete wheat-grain silo under an initial damage. The CFRP bands were used to ensure the concrete wheat-grain silo. The analytical method based on the Reimbert theory and the Eurocode 1 Part 4 method, as well as FEM using software Abaqus 6.14 [18], are all adapted for pressure and stress analyses. A methodology using 3D numerical analysis has been adopted to assess CFRP reinforced CS, which was performed to optimize the CFRP reinforcement according to plans for the numerical simulation. This simulation has been developed as a function of the width of the band, the gap between two bands, the height of the reinforcement and the number of banding layers.

\section{Adopted methodology}

The methodology for assessing the behaviour of a CFRP reinforced $\mathrm{CS}$, which has conventional dimensions, follows the geometrical models illustrated in Figure 1.

The corresponding geometrical characteristics are given in Table 1.

This investigation is characterised by 4 modes for CFRP reinforcement of a CS. Each mode is generated from the results of the preceding mode results to obtain a continuous chronological order for the CFRP reinforcement analyses. The CFRP bands start at the cylinderhopper joint by mounting 2 bands of CFRP above and below the joint. In fact, the 2 bands meet at the cylinderhopper joint with no gap forming one band layer. This mode is attributed to a single layer joint (SLJ) of 2 bands of $0.3 \mathrm{~m}$ width. As more layers are added on the single band, then the new reinforcement will consist of 2 bands mounted above and below the joint but each band is formed with more than one layer of CFRP. Therefore, the latter is attributed to multi-layer joint (MLJ). Before assigning the modes, analyses of the pressure and damage to the unreinforced CS were conducted.

For the CS without reinforcements, in this case, analytical Reimbert and Eurocode methods were first carried out to determine the normal pressure on the silo wall and the vertical pressures. Then numerical simulations using the Abaqus software were conducted to compare the pressures to analytical results and to detect the initial damage caused during the first grain loading. 
Table 2. Mechanical and physical properties for concrete and reinforcement materials.

\begin{tabular}{llll}
\hline Properties of concrete and the reinforcement material & Concrete & FeE40 steel & CFRP \\
\hline Young's modulus $(\mathrm{MPa})$ & 20800 & 200000 & 46000 \\
Poisson's ratio & 0.175 & 0.3 & 0.27 \\
Density $\left(\mathrm{kg} / \mathrm{m}^{3}\right)$ & 2500 & 7850 & 1750 \\
Tensile strength $(\mathrm{MPa})$ & & 620 & \\
Compressive strength $(\mathrm{MPa})$ & 25 & & \\
\hline
\end{tabular}

Table 3. Mechanical properties of wheat grains.

\begin{tabular}{lll}
\hline Properties & Designation & Mean values \\
\hline Angle of dilation $\left(^{\circ}\right)$ & $\psi$ & 17.6 \\
Internal friction angle $\left(^{\circ}\right)$ & $\phi$ & 25 \\
Poisson ratio & $v$ & 0.33 \\
Grain-wall friction coefficient & $\mu$ & 0.44 \\
Young's modulus $(\mathrm{MPa})$ & $E$ & 5.129 \\
Density $\left(\mathrm{kg} / \mathrm{m}^{3}\right)$ & $\Delta$ & 840 \\
\hline
\end{tabular}

Mode 1: In the MBCFRP mode, multi-band CFRP silos were reinforced to over $1 / 3$ the total height represented by $\mathrm{H}_{\mathrm{CFRP}}$, which equals $10 \mathrm{~m}$. It should be stated that the geometrical model for the numerical simulations contained the first apparent initial damage. Commercial CFRP bands with a $30 \mathrm{~cm}$ width were used. In this mode, the aim was to optimize the number of mounted CFRP bands. This depends on the gap between bands. So, gaps of $40 \mathrm{~cm}$, $30 \mathrm{~cm}, 20 \mathrm{~cm}$ and $10 \mathrm{~cm}$ were progressively adopted until the best results were obtained.

Mode 2: In the HMBCFRP mode, multi-band, CFRP reinforcement of the hopper wall was performed, while the optimized results from Mode 1 were used to optimize the banding height.

Mode 3: In the $\mathrm{SLJ}_{\mathrm{CFRP}}$ mode, CFRP reinforcement of a SLJ joint in the cylindrical-hopper joint zone was performed to reduce the number of CFRP bands.

Mode 4: In the $\mathrm{MLJ}_{\mathrm{CFRP}}$ mode, $\mathrm{CFRP}$ reinforcement of MLJs in the cylindrical-hopper joint zone was performed to improve the performance of the CFRP bands.

\section{Materials and properties}

The properties of the materials in a CS and those used for reinforcement are presented in Table 2. The model for concrete damaged plasticity (CDP) describes the mechanical behaviour of concrete [18]. The properties of steel, which is also used to reinforce concrete, were obtained through experimental tensile tests performed on specimens prepared from FeE40 steel bars. The steel behaviour is elasto-plastic with isotropic hardening.

External reinforcement is provided by carbon fiberbased, unidirectional fabric that is coated with bicomponent epoxy resin suitable for the weaving processing. The carbon fibers were selected because of their appreciable properties in civil engineering applications, such as those requiring a high stiffness, high tensile strength, low weight, high chemical resistance, high temperature tolerance and a low thermal expansion of its mechanical characteristics (e.g. the modulus of elasticity and the tensile strength). The CFRP strips had linear elastic behavior. The characteristics of the cast material/resin were measured in traction [19].

The main properties of wheat, in a dry state, are summarized in Table 3. They were determined in the work of Moya [20-22] and used in the studies of Vidal [7] and those of Abdel-Rahim [23].

\section{Pressure analysis}

\subsection{Reimbert and Eurocode pressure analyses}

Fundamental theories and methods for the calculation of pressure on silo walls use the notion of mobilized friction forces on the wall. The first theory was attributed to Janssen, which is based on the principle of the limit state of plastic equilibrium described by the Mohr Coulomb criterion [24,25]. Among the latter developed theories, the Reimbert method [26] is commonly used and adopted, which is also true of the present work, particularly for deep silos when calculating the filling process. In deep-depth silos, the lateral pressure reaches its maximum value because the weight of a horizontal layer of the ensiled material is equilibrated by the friction of the wall, where the pressure is the same above and below, and tends towards the same asymptotic limit.

In addition to the Reimbert method, the Eurocode 1 Part 4 method has also been used to calculate the normal and vertical pressures exerted on silo walls. The Euro code proposes the Janssen theory for these slender silos, and the 
Table 4. The Reimbert and Eurocode 1-Part 4 engineering models.

\begin{tabular}{llll}
\hline & Pressure & Normal wall pressure & Vertical pressure \\
\hline \multirow{2}{*}{ Methods } & Reimbert (1) & $P_{n}=P_{\max }\left[1-\left(\frac{Z}{A}+1\right)^{-2}\right]$ & $P=\Delta\left[Z\left(\frac{Z}{A}+1\right)^{-1}+\frac{h}{3}\right]$ \\
& Eurocode (2) & $P n=\frac{\Delta A}{\mu U} C z(Z)$ & $P_{V}=\frac{Z A}{K s \mu U} C z(z)$ \\
\hline
\end{tabular}

Table 5. Description for the reinforcement of concrete.

\begin{tabular}{llll}
\hline Reinforcement & Cylindrical wall & Hopper & Distance between bars $(\mathrm{cm})$ \\
\hline Meridional & 2 layers $\varnothing 10$ & 2 layers $\varnothing 10$ & 20 \\
Circumferential & 2 layers $\varnothing 14$ & 2 layers $\varnothing 16$ & 15 \\
\hline
\end{tabular}

Reimbert theory for squat silos. Table 4 summarizes the engineering models for these two analytical methods $[1,27,28]$.

With:

$$
\begin{gathered}
Z_{0}=\frac{A}{K s \mu U} \\
C z(Z)=1-e^{\left(-\frac{Z}{Z_{0}}\right)}
\end{gathered}
$$

\subsection{Numerical pressure analysis}

In the last two decades, finite element methods based on the Abaqus software have been used in the analyses of silo structures $[6,7,15,29]$. The geometry and various materials (e.g. concrete, steel and CFRP) are contained within the silo structure. In addition to their interactions and the behavioural problems arising from exerted pressures and flows, the development of the present numerical approach was achieved in three dimensions using the finite element method available in Abaqus version 6.14. Real threedimensional geometrical modelling of silos made on concrete was carried out to conduct a non-linear analysis of silo walls using the elasto-plastic behaviour of the materials. Incremental compulsory displacement calculation is adopted and details of the numerical models are developed in the following sections.

\subsubsection{Geometrical model}

The geometrical model for the silo consists of two parts: a cylindrical shaped part and a centred hopper-shaped part (Fig. 1). The geometrical characteristics of the silo are given in Table 1.

\subsubsection{Structure model}

A thickness-to-diameter ratio of $0.03(<1 / 15)$ suggests that the structure of the silo can be considered as a thin shell; therefore, the effect of transverse shear deformation was neglected. The cylindrical part and the hopper of the silo wall were modelled with S4R elements, where each element is a 4-node, quadrilateral, shell element with reduced integration, containing five section Gaussian integration points. Circumferential and meridional modelling of the rebar in silos was defined as layers for the uniaxial reinforcement of the shell elements. The concrete has been reinforced in the cylindrical part and in the hopper with steel bars of respectively $14 \mathrm{~mm}$ and $16 \mathrm{~mm}$ diameter with their relative distance between bars. Details for steel reinforcement of the silo are given in Table 5. The CFPR material was modelled as S4R shell elements.

\subsubsection{Modeling of the granular material}

The wheat was modeled using three-dimensional elements, continuum three-dimensional eight nodes, reduced integration (C3D8R). The wheat behavior was considered elasto-plastic law, which enabled use of the Drucker-Prager criterion for the plastic part; this criterion was used for the calculation of silos in several works $[6,7,13,16,24]$. This model is based on the yield surface (Eq. (5)).

$$
F=\alpha I_{1}+\sqrt{J_{2}}=k
$$

where $\alpha$ and $k$ are constants that depend on the internal friction angle and on the cohesion of the stored material respectively, $I_{1}$ is the first invariant of the stress tensor and $J_{2}$ is the second deviatoric invariant.

A parametric study was carried out as a function of the internal friction angle of the wheat, the coefficient of friction and the Poisson's coefficient to examine the convergence of this model using the values given in Table 3 .

\subsubsection{Description of the CDP model behaviour}

The validity of the CDP model for the prediction of damage is described in references [30,31]. Basak and Paul [32] reported the effectiveness of the model for modelling reinforced concrete shells subjected to internal pressures. The model assumes that the two main failure mechanisms are tensile cracking and the compressive crushing of the concrete material. It consists of a combination of nonassociated multi-hardening plasticity with scalar (isotropic) damaged elasticity to describe the irreversible damage that occurs during the fracturing process. 
Table 6. Design of the numerical simulations used to analyze the CFRP reinforced concrete silo.

\begin{tabular}{|c|c|c|c|c|c|c|c|c|c|c|}
\hline No. & $\begin{array}{l}\text { Mode of } \\
\text { reinforcement }\end{array}$ & $\begin{array}{l}H_{\mathrm{CFRP}} \\
(\mathrm{m})\end{array}$ & $\begin{array}{l}H_{\mathrm{HCFRP}} \\
(\mathrm{m})\end{array}$ & $\begin{array}{l}H_{\mathrm{SLJ}} \\
(\mathrm{m})\end{array}$ & $H_{\mathrm{MLJ}}(\mathrm{m})$ & $\begin{array}{l}\text { CFRP band } \\
\text { width }(\mathrm{m})\end{array}$ & $\begin{array}{l}\text { Gap between } \\
\text { bands }(\mathrm{m})\end{array}$ & $\begin{array}{l}\text { Number of } \\
\text { band layers }\end{array}$ & $\begin{array}{l}\text { Number of } \\
\text { bands }\end{array}$ & Task \\
\hline 1 & $\begin{array}{l}\text { Concrete silo } \\
\text { without CFRP }\end{array}$ & - & - & - & - & - & - & - & - & Pressure/damage ${ }^{*}$ \\
\hline 2 & & & - & - & - & & 0.4 & & 15 & \multirow{2}{*}{$\begin{array}{l}\text { Optimizing the } \\
\text { CFRP reinforcement } \\
\text { gap }\end{array}$} \\
\hline 5 & & & - & - & - & & 0.1 & & 26 & \\
\hline 6 & Mode 2 & - & $0-3.3$ & - & - & 0.3 & 0.2 & 1 & 7 & $\begin{array}{l}\text { Optimizing the } \\
\text { CFRP reinforcement } \\
\text { height }\end{array}$ \\
\hline 8 & Mode 4 & - & - & - & $2.7-3.3$ & $2 \times 0.3$ & 0 & $2-5$ & $4-10$ & $\begin{array}{l}\text { Improving the } \\
\text { performance of } \\
\text { CFRP reinforcement }\end{array}$ \\
\hline
\end{tabular}

* Damage in modes 1-4 was analyzed according to the first damage obtained during the filling of silos without CFRP with wheat grains. below:

The main characteristics of the model are presented

\section{Strain rate decomposition}

The strain rate is given by equation (6),

$$
\varepsilon^{\prime}=\varepsilon^{\prime e l}+\varepsilon^{\prime p l}
$$

where $\dot{\varepsilon}$ is the total strain rate, $\varepsilon^{\prime e l}$ is the elastic strain rate and $\varepsilon^{\prime p l}$ is the plastic strain rate.

\section{Stress-strain relations}

The engineering stress-strain relationship is dependent on the elastic damage scalar given by equation (7).

$$
\sigma=(1-d) D_{0}^{e l}:\left(\varepsilon-\varepsilon^{p l}\right)=D^{e l}:\left(\varepsilon-\varepsilon^{p l}\right)
$$

where $D_{0}^{e l}$ is the initial material elastic stiffness, $D^{e l}=(1-d) D_{0}^{e l}$ is the elastic stiffness of the damaged material and $d$ is the scalar damage variable for the stiffness; the damage variables can take values from zero, which represents the undamaged material, to one for fully damaged material.

Reinforced concrete codes neglect the tensioned concrete, while the tensioned concrete between the cracks contributes substantially to the rigidity. This is the result of "tension stiffening" in the CDP model. Degradation of the elastic stiffness is characterized by two damage variables $d t$ and $d c$ which are assumed to be functions of the plastic strain and are plotted respectively as a function of the cracking strain and the inelastic strain. Details regarding $d t$ and $d c$ are fully developed in the literature [18].

\subsubsection{Loading, interface and mesh}

The applied loads consist of a gravity load and a vertical friction load under static conditions. Coulomb's friction model is used to describe the interaction between the silo wall and the solid wheat bulk. Since the cohesion sliding resistance between both materials $c$ is assumed to be zero, the wall friction coefficient $(\mu=0.44)$ was the only required parameter. Hence, equivalent shear stress, $\tau$, which is given in equation (8), is linearly dependent on the wall normal pressure, $P$.

$$
\tau=\mu P+c
$$

To simulate the contact of the stored material with the wall, a surface-to-surface contact model was used with the penalty method algorithm.

One of the main issues in modelling the CFRP reinforcement of a $\mathrm{CS}$ is to solve the nature of contact between the concrete wall surface and the CFRP bands. This is achieved by using the constraint parameter in the Abaqus software [33], which considers that the wall-CFRP contact is perfectly adherent.

The filling process was modelled according to the procedure described by the method for increasing the gravity load $[6,24,34]$.

A sensitivity analysis of the mesh was carried out using an increasing number of elements. The final total number of chosen elements was 13531 , which provides a good relative convergence accuracy for the pressure values. 


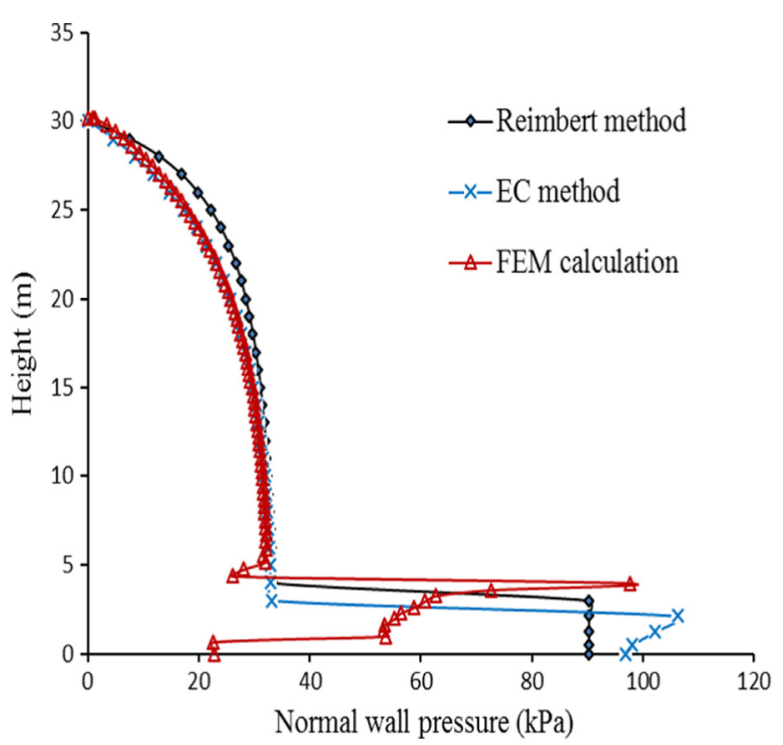

Fig. 2. Analytical and numerically normal pressure in the concrete silo.

\subsubsection{Design of the numerical simulations}

The design of the numerical simulations was determined from the beginning of the investigation to ensure that, when a simulation is carried out, the next one should produce complementary information that will help to optimize the CFRP reinforced CS. Therefore, the design of the numerical simulations is presented chronologically in Table 6 .

\section{Results and discussion}

\subsection{Pressure analyses for the CFRP reinforced CS}

\subsubsection{Pressure predictions for CS}

Results of the evolution of the normal pressure on the silo wall, which was determined with both analytical and numerical methods, are plotted as a curve of silo height as a function of the applied normal pressure to the wall (Fig. 2). The height-pressure curves obtained with the 3 engineering models followed the same asymptotic trend, while the pressure values were almost equal in the cylindrical part of the silo and reached $33 \mathrm{kPa}$. When approaching the hopper, the normal pressure increased drastically until it reached a peak value. Meanwhile, the results revealed that the three applied methods do not give the same peak value. They also did not agree around the zone where this peak value occurred. In fact, the Reimbert method suggested that a peak value of $89.5 \mathrm{kPa}$ is observed at the cylinder-hopper joint, whereas the Eurocode method reveals a higher pressure with a peak value of $106.2 \mathrm{kPa} 2.15 \mathrm{~m}$ below the cylinder-hopper joint. Meanwhile, the FEM method shows a pressure peak value of $98.8 \mathrm{kPa}$ at almost $4 \mathrm{~m}$ above the cylinder-hopper joint. With regards to pressure, it is interesting to consider the results reported in steel silos by Louetri et al. [17]. In fact, near the cylinder-hopper joint results are in good agreement with those obtained in the present work suggesting that the normal pressure increases drastically. Meanwhile the present work is focused on the reinforcement of damaged CS rather than studying the elastic behavior of CFRP reinforced steel

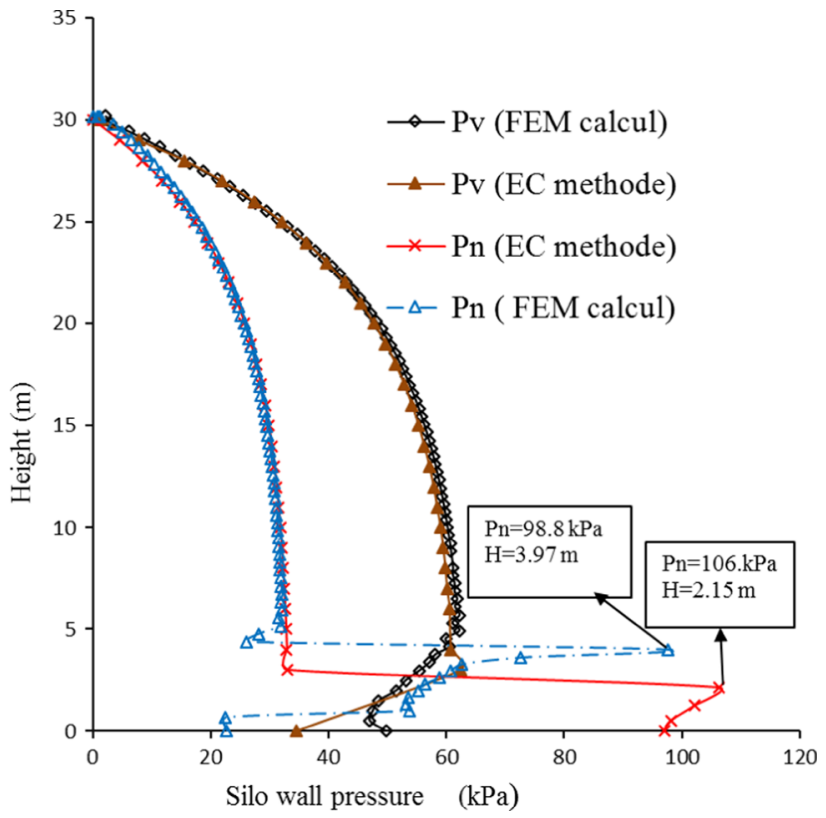

Fig. 3. Evolution of normal and vertical pressures in the CS.

silo.As expected $[12,35,36]$, the additional pressure caused by the dense quantity of stored material enhanced the phenomenon by creating a peak at the top of the hopper and then decreased as the section of the hopper decreased. This is observed through the behaviour of the vertical pressures, which followed the same asymptotic trend as the normal wall pressures; however, their values were 2 times higher in the cylindrical part when approaching the hopper.

Figure 3 shows comparative plots of the normal and vertical pressures in the CS. Meanwhile, the vertical pressure calculated with the three methods was in good agreement for the cylindrical part of the silo. For the hopper, the results of Reimbert method were higher and were found not to be representative upon comparing them to Eurocode and the numerical methods.

It is very difficult to say where the peak pressure occurred with the analytical method, whereas the Abaqus FEM method produced pictures to show what could really happen at the cylinder-hopper junction. Figure 4 gives a better picture of the behaviour of the pressure at the cylinder-hopper joint. This is in good agreement with events reported in literature reviews $[6,7,29]$.

\subsubsection{Effect of CFRP reinforcement}

Investigation of the effect of CFRP reinforcement on silo walls was conducted during the operation of grain filling and when the filling was completed. Figure 5 shows the effect of CFRP reinforcement on the silo walls. The distribution of the normal pressure in the silo reinforced with CFRP followed a similar asymptotic trend as that obtained for a CS. Their pressure values were almost similar to the cylindrical part of the silo. At the cylinderhopper joint, CFRP reinforcement caused a decrease in the peak pressure, where a significant drop of 26\% was obtained. This effect led to exploratory analyses on the eventual damage in the cylinder-hopper joint of the silo. 


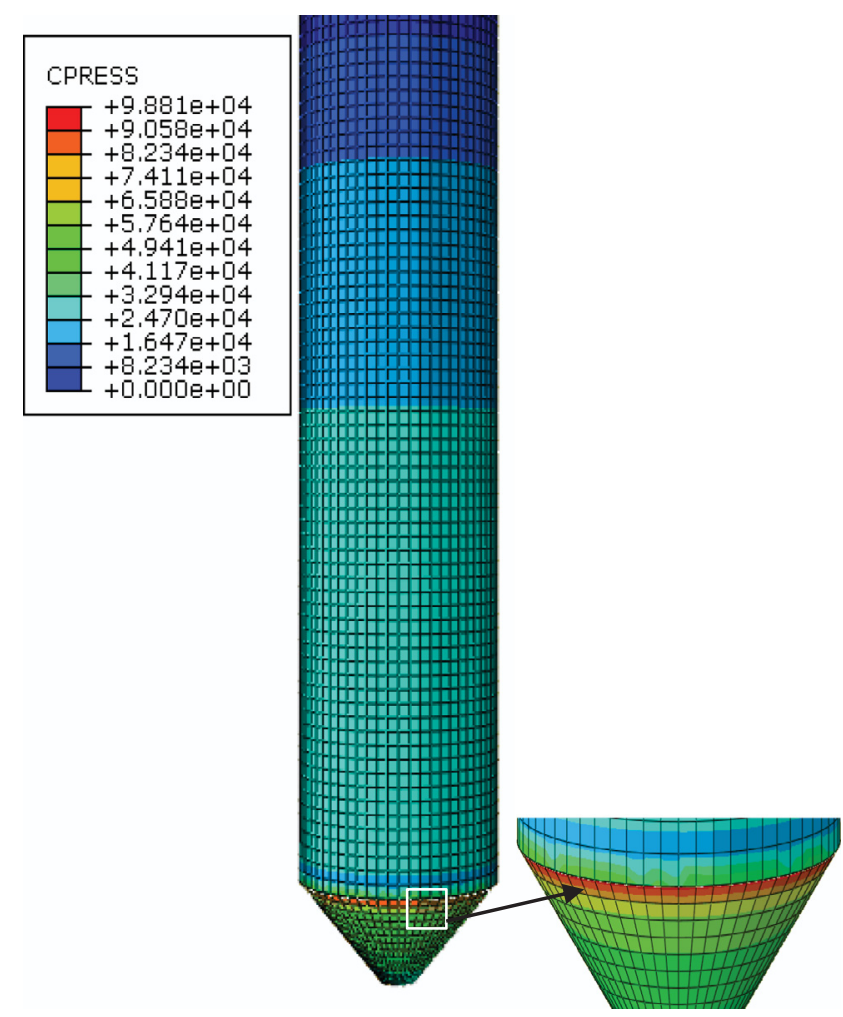

Fig. 4. FEM distribution of the normal pressure in silos.

\subsection{Damage analyses in the CFRP reinforced CS}

\subsubsection{Initial damage prediction}

CFRP is employed to reinforce damaged CSs. Therefore, the first damage analysis consists of observing the behavior of the CS without reinforcement since the first grain filling. Then, numerical simulations were conducted in a CFRP reinforced CS. The FEM method offers possibilities, such as locating the elements of the structure that are susceptible to cracking under the maximum pressures and inquiring about the status of the damage. For damage, the zone most sensitive to cracking appears to be beneath the cylinder-hopper joint. For the CS and the CFRP reinforced silo, Figure 6 shows the localization of initial damage at the top of the hopper, which is located just below the cylinder-hopper joint.

The initial damage can be determined when the grain filling operation is conducted by plotting the evolution of the damage as a function of the ratio of the grain filling volume to the total volume of the silo. It should be stated that the bulk storage of grain is achieved progressively by increasing the gravity loads method in 5 steps. Figure 7 shows the evolution of damage in the CS and in the CFRP reinforced CS until the silo was completely filled.

The initiation of damage in the CS was observed from a ratio of grain filling volume to the total volume, which had a value of 0.35 . A small damage value of about 0.005 was detected and then, when the silo was full, it increased significantly following an exponential trend until it reached a value of 0.152 . In the CFRP reinforced CS, damage evolution followed a linear trend with a very

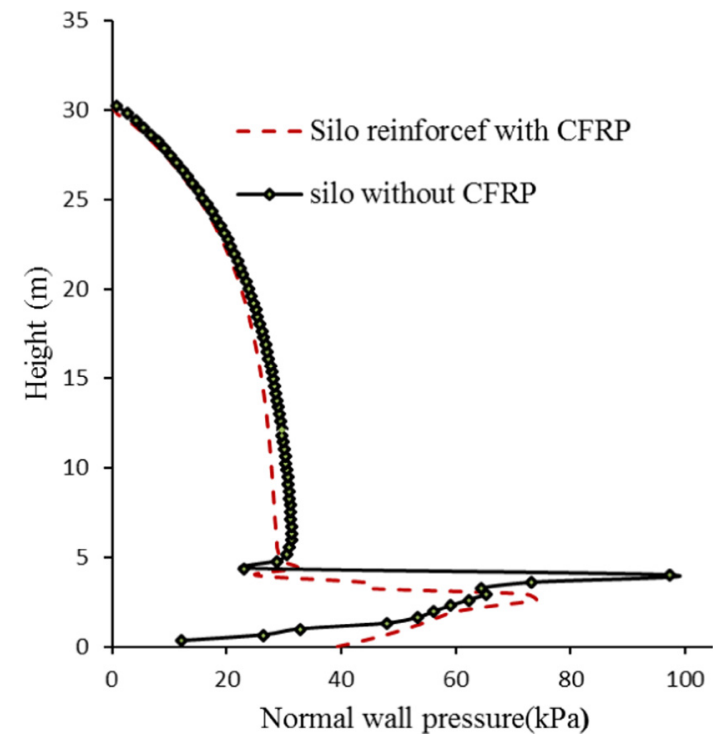

Fig. 5. Effect of CFRP reinforcement on the horizontal pressure in the CS.

small slope that started at a grain filling volume to total volume ratio of 0.62 , where a damage value of 0.006 was observed, and ended at a value of 0.047 when the silo was completely full. Hence, CFRP reinforcement reduces the initial damage in a CS by 3 at the end of the grain filling process.

\subsubsection{Effect of CFRP reinforcement on the CS with initial damage}

From the first operation of silo filling, a damage of 0.152 was generated and could grow as the silo was unloaded and filled again. Therefore, it is interesting to reconsider the numerical simulations for the CS, when initial damage exists, to determine the evolution of damage as a function of the normal pressure. Figure 8 illustrates a plot of damage as a function of the normal pressure in both a concrete and a CFRP reinforced silo with initial damage.

As the pressure increased as a function of height, the initial damage was constant for an exerted pressure of up to $80 \mathrm{kPa}$. By the time the critical height of grain filling was reached, the damage was found to have increased as a function of the exerted pressure. At the end of the grain filling process in the CS, damage jumped to 0.171 and 0.161 for the concrete and CFRP reinforced silos respectively, which had respective pressures of $102.66 \mathrm{kPa}$ and $95.35 \mathrm{kPa}$. The maximum ratio for the damage in CS to CFRP reinforced silos is $6 \%$, which represents the beneficial effect of CFRP reinforcement in CSs.

\subsection{Optimization of CFRP bands}

The number of CFRP bands depends on the height of the silo to be reinforced, the width of the band, the gap between the two bands and the number of layers in each CFRP band. In the present work, a simulation plan was produced according to the chronological and eventual events resulting from one simulation to another. 

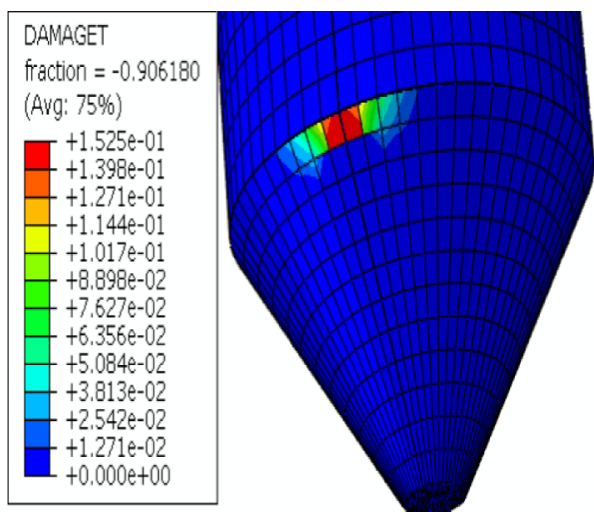

(a)
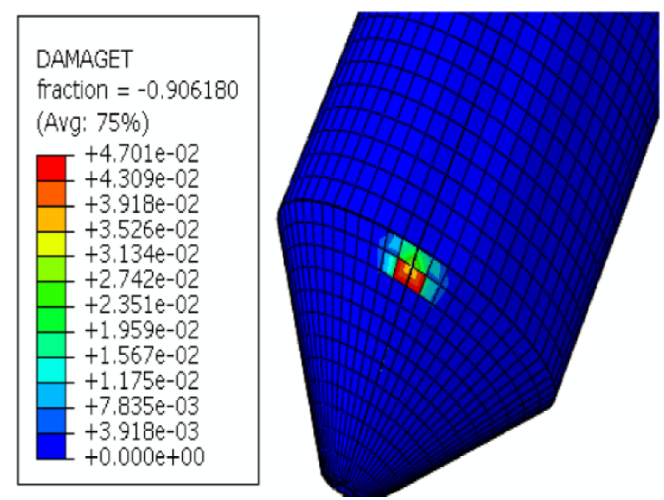

(b)

Fig. 6. Localization of damage at the cylinder-hopper joint: (a) in CS and (b) in a CFRP reinforced CS.

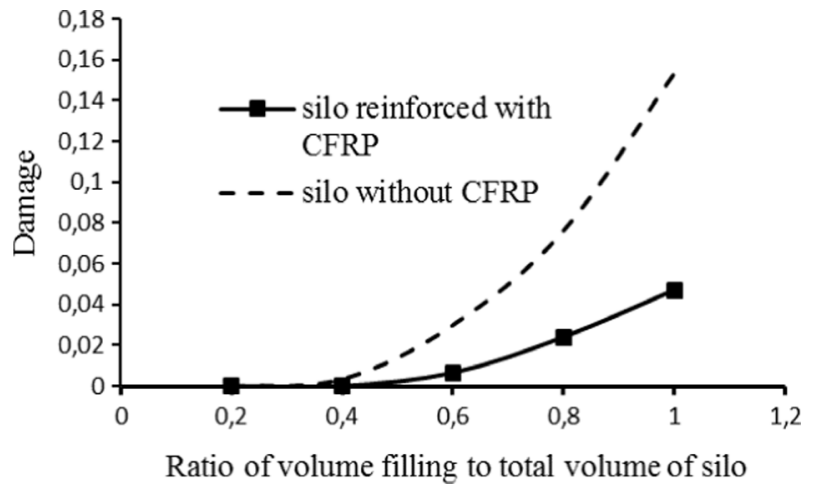

Fig. 7. Prediction of damage initiation.

\subsubsection{The effect of CFRP reinforcement gaps on silo damage}

Four modes for CFRP bands were proposed. In the cylindrical part of the silo, the exerted pressure was almost the same until the hopper part where the peak pressures appeared. In Mode 1 , the reinforced height was $10 \mathrm{~m}$ or $1 / 3$ of the total silo height. Four gaps were adopted. The gap was decreased from $0.4 \mathrm{~m}$ by increments of $0.1 \mathrm{~m}$, which generated an increase in the number of CFRP bands as shown in Table 5 . As different peak pressure values were obtained, they should be alternatively different damage values (Fig. 9).

The investigation on the evolution of damage as a function of the number of CFRP bands, which is expressed by the gap between two bands, showed that, even when the concrete was reinforced, the damage was higher as it reached 0.205 for a gap of $0.4 \mathrm{~m}$ and decreased as the gap decreased. However, at a gap of $0.1 \mathrm{~m}$, it increased again. However, at a gap of $0.1 \mathrm{~m}$, it increased again. This suggests that the reinforcement should be added with quite larger gaps, otherwise for smaller gaps, there is too much compressive pressure generated on the concrete leading to worse behavior. Therefore, the reinforcement with smaller gaps is no more interesting. For gaps of $0.3 \mathrm{~m}$ and

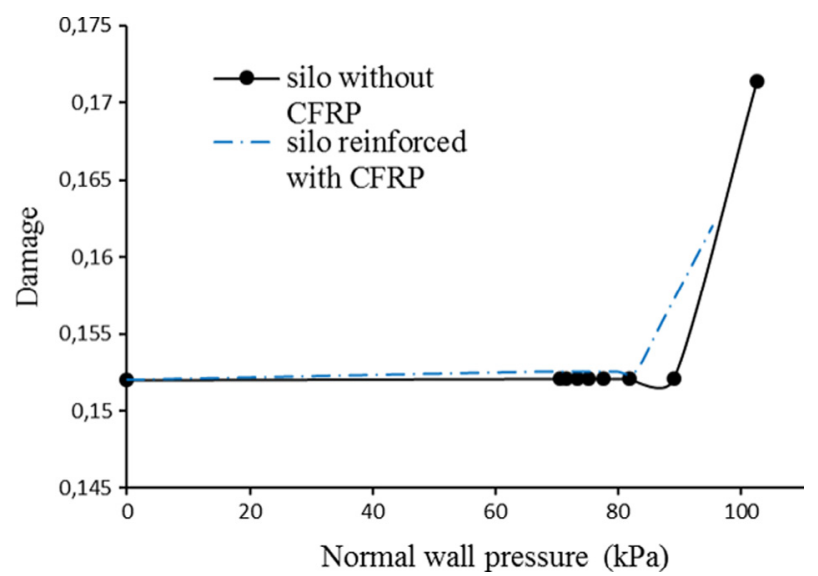

Fig. 8. Evolution of damage as a function of the normal pressure in a CS with and without CFRP reinforcement.

$0.2 \mathrm{~m}$ the damage is almost respectively similar, 0.163 and 0.161 . When considering the cost of reinforcement, then the best configuration is the reinforcement with $0.3 \mathrm{~m}$ gap.

The next step is to determine how this number could be reduced.

\subsubsection{Effect of CFRP reinforcement gaps on stresses in silo}

Stress analyses on optimized CFRP reinforced CSs consist of observing the redistribution of circumferential and meridional stresses in the cylindrical part and in the hopper of a silo. Figures 10-13 show the circumferential and meridional stresses in the cylindrical part and in the hopper part.

Although there are both circumferential and meridional stresses on the cylindrical part, it was noticed that the four curves for the reinforcement with different gaps coincide with the curve for a non-reinforced silo, except for a slight decrease in the circumferential stress at the lowest level of the evaluated wall at $2 \mathrm{kPa}$. This is explained by the weak pressure over this part of the wall. However, at the level of the hopper, there were important reductions in circumfer- 


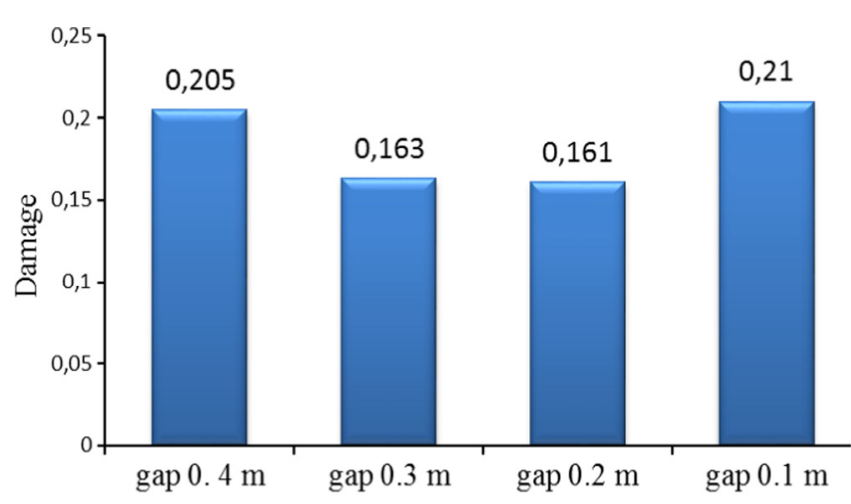

Gap between the CFRP bands in mode 1

Fig. 9. Evolution of damage as a function of the number of CFRP bands.

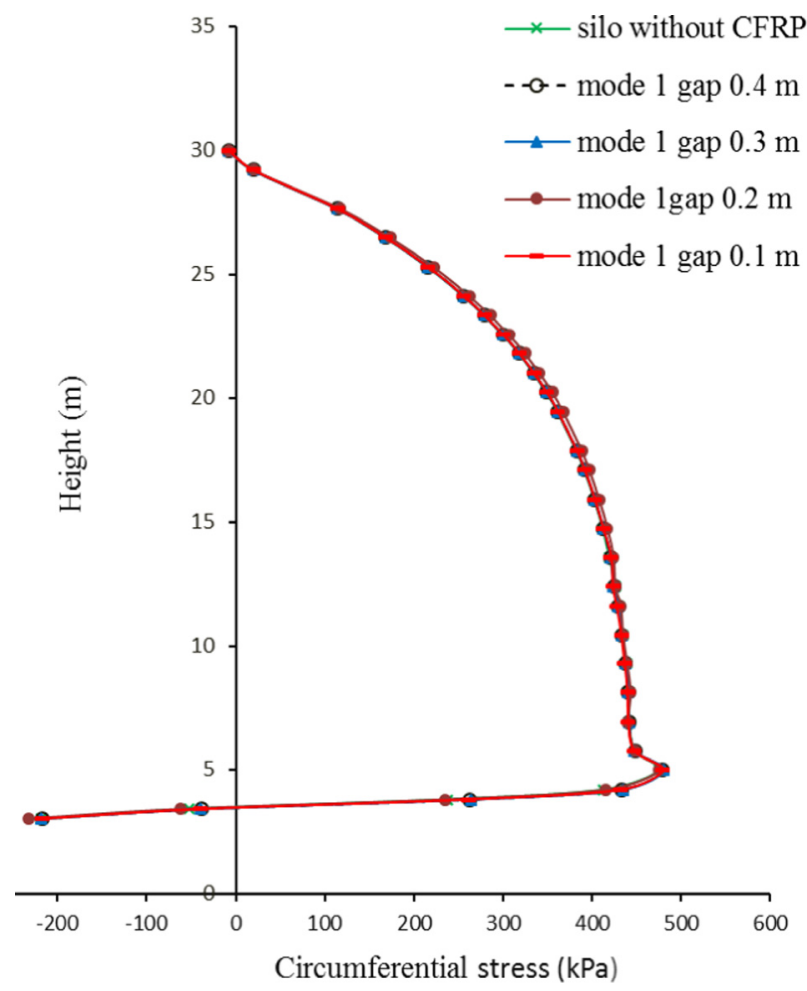

Fig. 10. Distribution of circumferential stresses in the cylindrical part.

ential and meridional stresses for a gap of $0.20 \mathrm{~m}$. This reduction was about $31 \%$ and $32 \%$ for the circumferential and meridional stresses respectively.

\subsubsection{Optimization of the height CFRP reinforcement}

From Sections 5.3.1 and 5.3.2, the best configuration was for a height that was $1 / 3$ of the total height and a gap of $0.2 \mathrm{~m}$. In the present section, the effect of the height is studied by considering the height of the hopper with an additional distance corresponding to the width of the CFRP band mounted just above the cylinder-hopper joint of $0.3 \mathrm{~m}$. This is attributed to Mode 2 for CFRP

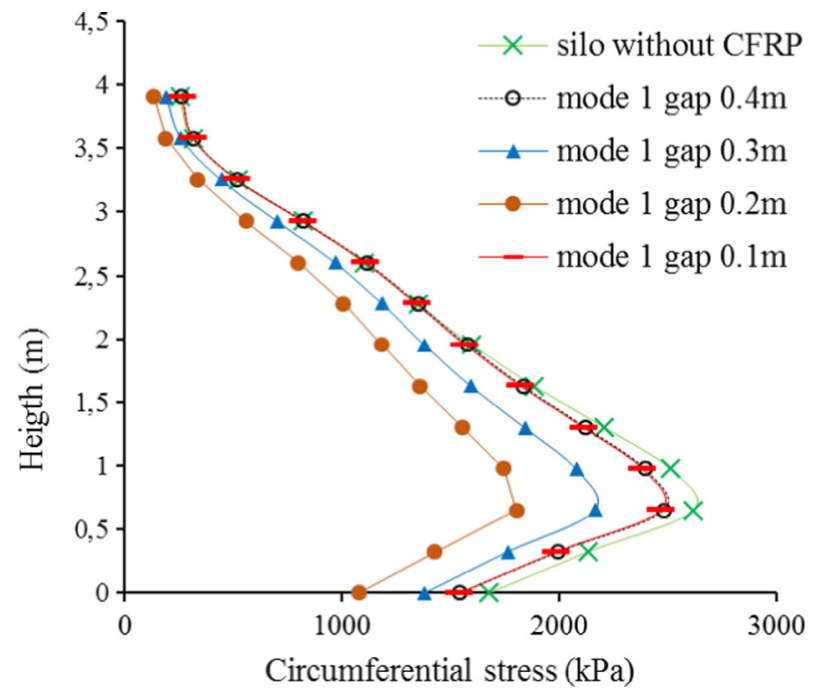

Fig. 11. Distribution of circumferential stresses in the hopper.

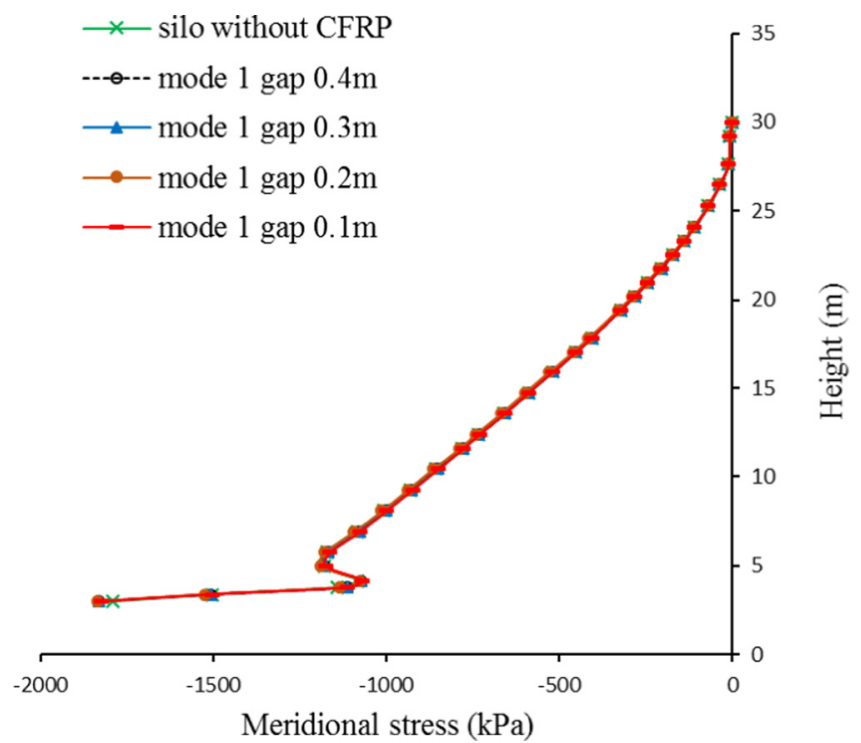

Fig. 12. Distribution of meridional stress in the cylindrical part.

reinforcement, which is shown in Table 5 , where numerical simulations were conducted for a height of $3.3 \mathrm{~m}$. The damage for Mode 2 was 0.1615 , which was not very different from the result obtained for Mode 1 (0.1617). This shows that the reinforcement height could be reduced to the hopper height.

5.3.4 Optimisation of CFRP bands in the hopper of a grain silo

The results obtained in Section 5.3.3 suggest that the number of CFRP bands could be reduced to 2 if Mode 3 is applied. Therefore, the next simulations were performed with 2 CFRP bands mounted on the upper side and beneath the side of the cylinder-hopper joint. The results are given in Table 7 . These results show that, as the same damage used for Mode 2 is applied, the reinforcement could use 2 CFRP bands 
Table 7. Optimization of CFRP bands for reinforcing concrete silos.

\begin{tabular}{lllllllll}
\hline No. & $\begin{array}{l}\text { Mode of } \\
\text { reinforcement }\end{array}$ & $\begin{array}{l}\mathrm{H}_{\mathrm{SLJ}} \\
(\mathrm{m})\end{array}$ & $\begin{array}{l}\mathrm{H}_{\mathrm{MLJ}} \\
(\mathrm{m})\end{array}$ & $\begin{array}{l}\text { CFRP band } \\
\text { width }(\mathrm{m})\end{array}$ & $\begin{array}{l}\text { Gap between } \\
\text { bands }(\mathrm{m})\end{array}$ & $\begin{array}{l}\text { Number of } \\
\text { band layers }\end{array}$ & $\begin{array}{l}\text { Number of } \\
\text { bands }\end{array}$ & $\begin{array}{l}\text { Damage value } \\
\text { mode }\end{array}$ \\
\hline 1 & Mode 3 & $2.7-3.3$ & - & $2 \times 0.3$ & 0 & 1 & 2 & 0.161 \\
2 & & & & & & 2 & 4 & 0.157 \\
3 & & & & & & 3 & 6 & 0.156 \\
4 & Mode 4 & - & $2.7-3.3$ & $2 \times 0.3$ & 0 & 4 & 8 & 0.152 \\
5 & & & & & & 5 & 10 & 0.154 \\
\hline
\end{tabular}

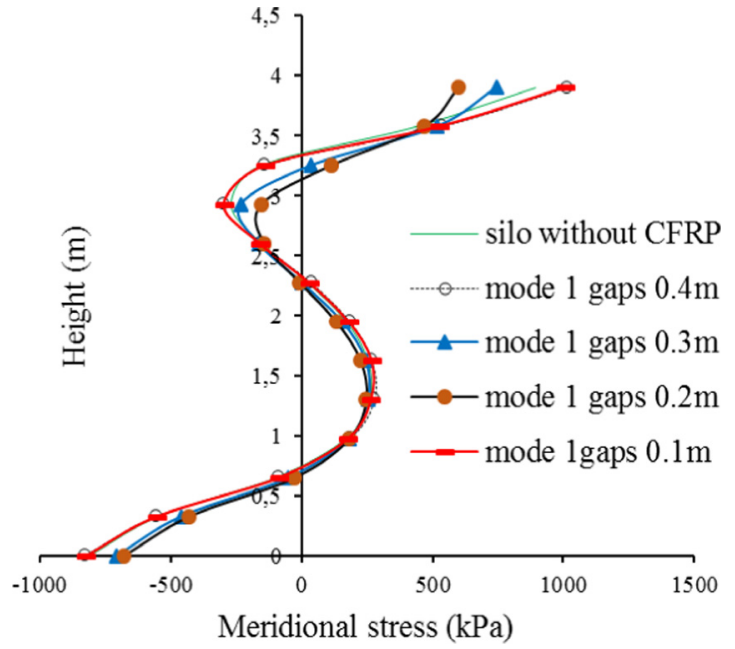

Fig. 13. Distribution of meridional stress in the hopper part.

at the cylinder-hopper joint as presented in Mode 3 (Fig. 1). There was no need to use multi-layer CFRP bands because the results from Mode 4 revealed a slight decrease in the damage, which was particularly true when 4 layers were used. Hence, the best solution was to adopt Mode 4 , which is economically very interesting as only 2 bands were used and resulted in less damage. Better performance could have been obtained with 4 band layers, but the decision should result from a common agreement among the silo managers.

\section{Conclusions}

The present work proposed FEM investigations on a CFRP reinforced wheat-grain CS under initial damage. CFRP reinforcement was used in a simulation plan based on width of the bands, the gap between two bands, the height of the reinforcement and the number of banding layers. The investigation was carried out using analytical and numerical engineering methods.

The Reimbert and the Eurocode 1 Part 4 methods were applied to the cylindrical part of the silo and agreed with the normal pressure values obtained using FEM analyses. The normal and vertical pressures increased with the filling height. While approaching the hopper part of the silo, peak normal pressures were obtained, but they differed in values and in localization within the silo depending upon the engineering methods used.

Initial damage was also investigated in the CS using a 3D geometrical model. The analyses were then conducted with regard to the initial damage. The best solution was to use a CFRP reinforcement by mounting 2 CFRP bands that were $30 \mathrm{~cm}$ apart above and below the cylinderhopper joint. Increasing the number of banding layers could produce better performance as the damage was slightly decreased from 0.161 to 0.152 for 1 layer and 4 layers respectively. The use of CFRP as an alternative for repairing silos increases the volume of granular material that could be stored in a silo. This makes it possible to decrease the silo stresses by $32 \%$ when the gap between CFRP bands is of $0.3 \mathrm{~m}$.

The former solution is economically accessible; therefore, it can be used in real conditions for wheat-grain silo reinforcement to validate the present results.

\section{Nomenclature}

$a$

$c$

CDP

CFRP

$\mathrm{CS}$

$c_{Z}$

$d$

$d c$

$d t$

$d t$
$D_{0}^{\theta l}$
$D^{\theta l}$

$e$

EC

$f$

FEM

$h$

$H$

$H_{C}$

$H_{\mathrm{CFRP}}$

$H_{\underline{H}}$

$H_{\text {HCFRP }}$

HMBCFRP
$H_{\text {SLJ }}$
$H_{\mathrm{MLJ}}$
$I_{1}$
$J_{2}$

Interior surface of right section of silo cell Cohesion sliding resistance

Concrete damage plasticity

Carbon fiber reinforced polymer

Concrete silo

Janssen's coefficient

Scalar stiffness degradation variable

Uniaxial compression damage variable

Uniaxial tension damage variable

Initial (undamaged) elastic stiffness

Elastic stiffness

Young's modulus (MPa)

Eurocode

Yield surface

Finite element method

Height of silage (m)

Total height of silo $(\mathrm{m})$

Cylinder part height $(\mathrm{m})$

Height of reinforcement by CFRP (m)

Hopper height (m)

CFRP hopper height

Multi bands CFRP reinforcement of the hopper

Height single layer joint

Height multi-layer joint

First invariant of the stress tensor

Second deviatoric invariant of the stress tensor 


\begin{tabular}{|c|c|}
\hline$k$ & Constant of the Drucker-Prager model \\
\hline$K s$ & $\begin{array}{l}\text { Value of normal wall pressure/vertical } \\
\text { pressure }\end{array}$ \\
\hline $\mathrm{MB}_{\mathrm{CFRP}}$ & Multi bands CFRP \\
\hline $\mathrm{MLJ}_{\mathrm{CFRP}}$ & $\begin{array}{l}\text { Multi layers joint CFRP reinforcement } \\
\text { the cylindrical-hopper joint }\end{array}$ \\
\hline$P_{n}$ & $\begin{array}{l}\text { Normal wall pressure (horizontal pressure) } \\
(\mathrm{kPa})\end{array}$ \\
\hline$P_{n \max }$ & Maximal normal wall pressure $(\mathrm{kPa})$ \\
\hline$P_{v}$ & Vertical pressure $(\mathrm{kPa})$ \\
\hline$R c$ & Cylinder radius (m) \\
\hline$R h$ & Hopper hatch radius $(\mathrm{m})$ \\
\hline $\mathrm{SLJ}_{\mathrm{CFRP}}$ & $\begin{array}{l}\text { Single layer joint CFRP reinforcement of the } \\
\text { cylindrical-hopper joint }\end{array}$ \\
\hline$T w$ & Wall thickness $(\mathrm{m})$ \\
\hline$U$ & Interior perimeter \\
\hline$Z$ & Considered depth \\
\hline$Z_{0}$ & Parameter used to calculate the actions \\
\hline$\alpha$ & Constant of the Drucker-Prager model \\
\hline$\Delta$ & Density $\left(\mathrm{kg} / \mathrm{m}^{3}\right)$ \\
\hline$\phi$ & Internal friction angle $\left({ }^{0}\right)$ \\
\hline$v$ & Poisson ratio \\
\hline$\mu$ & Coefficient of friction on grain-wall \\
\hline$\psi$ & Angle of dilation $\left({ }^{0}\right)$ \\
\hline$\varnothing$ & Diameter of the reinforcing bars (mm) \\
\hline$\tau$ & Equivalent shear stress (MPa) \\
\hline$\dot{\varepsilon}$ & Total strain rate \\
\hline$\varepsilon l^{\theta l}$ & Elastic strain rate \\
\hline$\varepsilon^{p l}$ & Plastic strain rate \\
\hline$\sigma$ & Stress \\
\hline
\end{tabular}

Acknowledgments. The authors thank all the research team of the Laboratory of "Civil Engineering and Geo-Environment" of the Artois University of Lille for all helps brought and in particular Pr. Abdelkader Haddi for his support and his implication during the validation of work as well as the relevant ideas suggested.

\section{References}

[1] M. Reimbert, A. Reimbert, Silo théorie et pratique, Edition Eyrolles, Paris, 1982

[2] A. Orosz, G. Csaro, J. Tamaska, Strengthening of a 2000 wagon capacity reinforced concrete grain silo located at Marcali in Hungary, Concr. Struct. 1 (2000) 44-51

[3] D. Yonggang Ding, J. Wang, X. Wang, W. Feng, Performance analysis of concrete silo structure strengthened with carbon fiber reinforced polymer laminate, Adv. Mater. Res. 243-249 (2011) 5501-5505

[4] Er. A.B. Dutta, Study of type of failure in silo, Glob. Res. Anal. 2 (2013) 41-43

[5] L. Boonkok, Y.M. Hui, Protection of aged cement clinker silo against high impact and high temperature dicharge, in: L. Ye, P. Feng, Q. Yue (Eds.), Advances in FRP Composites in Civil Engineering, Proceedings of the 5th International Conference on FRP Composites in Civil Engineering, Beijing, China, 2010, pp. 415-418

[6] R.J. Goodey, C.J. Brown, The influence of the base boundary condition in modelling filling of a metal silo, Comput. Struct. 82 (2004) 567-579
[7] P. Vidal, E. Gallego, M. Guaita, F. Ayuga, Finite element analysis under different boundary conditions of the filling of cylindrical steel silos having an excentric hopper, J. Constr. Steel Res. 64 (2008) 480-492

[8] K. Saleh, P. Guigon, Mise en oeuvre des poudres - Stockage écoulement des silos, Techniques de L'ingénieur, J2225 (2012) 1-30

[9] N. Kuczynska, M. Wójcik, J. Tejchman, Effect of bulk solid on strength of cylindrical corrugated silos during filling, J. Constr. Steel Res.1 15 (2015) 1-17

[10] M.T. Abdel-Fattah, I.D. Moore, T.T. Abdel-Fattah, A numerical investigation into the behavior of groundsupported concrete silos filled with saturated solids, Int. J. Solids Struct. 43 (2006) 3723-3738

[11] A. Lapko, M. Gnatowski, J.A. Prusiel, Analysis of some effects caused by interaction between bulk solid and r.c. silo wall structure, Powder Technol. 133 (2003) 44-53

[12] J. Tejchman, Large scale silo tests, confined granular flow in silos, in: Experimental and Numerical, Investigations, Springer Series in Geomechanics and Geoengineering, Springer International Publishing, Switzerland, 2013

[13] Y. Wang, Y. Luc, J.Y. Ooi, A numerical study of wall pressure and granular flow in a flat-bottomed silo, Powder Technol. 282 (2015) 43-54

[14] A. Y. Elghazouli, J.M. Rotter, Long-term performance and assessment of circular reinforced concrete silos, Constr. Build. Mater. 10 (1996) 117-122

[15] F. Nateghi, M. Yakhchalian, Seismic behavior of reinforced concrete silos considering granular material-structure interaction, Procedia Eng. 14 (2011) 3050-3058

[16] I.M. Ezz El-Arab, Seismic analysis of RC silos dynamic discharge phenomena, Int. J. Eng. Adv. Technol. 4 (2014) 91-99

[17] L. Louetri, K. Djeghaba, E. Gallego, Numerical simulation of reinforcement in steel slender silos having concentric hopper with carbon fiber-reinforced polymer composites (study of the silos filling), Eur. J. Environ. Civ. Eng. 20 (2016) 809-830

[18] Simulia, Abaqus analysis: user's manual, Dassault Systèmes, 2014

[19] M.S. Ali, Enhancement of service life of prestressed concrete bridge, Thesis, Mcgill University, Canada, 2014

[20] M. Moya, P.J. Aguad, F. Ayuga, Mechanical properties of some granular agricultural materials used in silo design, Int. Agrophys. 27 (2013) 181-193

[21] M. Moya, M. Guaita, P. Aguado, F. Ayuga, Mechanical properties of granular agricultural materials, part 2, Trans. ASABE, 49 (2006) 479-489

[22] M. Moya, F. Ayuga, M. Guaita, P. Aguado, Mechanical properties of granular agricultural materials, Trans. ASAE, 45 (2002) 1569-1577

[23] H.H.A. Abdel-Rahim, Response of the cylindrical elevated wheat storage silos to seismic loading, IOSR J. Eng. 4 (2014) $42-55$

[24] H.A. Janssen, Tests on grain pressure silos, Zeitschrift des Vereines Deutscher Ingenieure 39 ( 1895) 1045

[25] J.Y. Ooi, J.F. Chen, R.A. Lohnest, J.M. Rotter, Prediction of static wall pressures in coal silos, Constr. Build. Mater. 10 (1996) 109-116

[26] M. Reimbert, L. Marcel, A. Reimbert. Silos, traité théorique et pratique, Bauverlag, 1961

[27] A. Guerrin, traité de béton armé construction divers, Tome XI, Bordas, Paris, France, 1979

[28] EN 1991-4, Eurocode 1. Basis of design and actions on structures-part 4: actions on silos and tanks, European Committee on Standarization, Brussels, 2006 
[29] Y. Wang, Y. Lu, J.Y. Ooi, Finite element modelling of wall pressures in a cylindrical silo with conical hopper using an Arbitrary Lagrangian-Eulerian formulation, Powder Technol. 257 (2014) 181-190

[30] B.L. Wahalathantri, D.P. Thambiratnam, T.H.T. Chan, S. Fawzia, A material model for flexural crack simulation in reinforced concrete elements using Abaqus, in: Proceedings of the First International Conference on Engineering, Designing and Developing the Built Environment for Sustainable Wellbeing, Queensland University of Technology, Brisbane, QLD, Australia, 2011, pp. 260-264

[31] O. Omidi, V. Lotfi, Finite element analysis of concrete structures using plastic-damage model in 3-d implementation, Int. J. Civ. Eng. 8 (2010) 187-203
[32] S. Basak, D.K. Paul, Damage evaluation of RCC containment structure subjected to internal pressure, Int. J. Eng. Sci. Technol. 4 (2012) 2823-2829

[33] M. Chandrashekhar, R. Ganguli, Large deformation dynamic finite element analysis of delaminated composite plates using contact-impact conditions, Comput. Struct. 144 (2014) 92-102

[34] S. Ding, G.G. Enstad, Stress distribution in the material and development of loads on the wall, Task Q. 7 (2003) 513-524

[35] D. Nortje, The anti-dynamic tube in mass flow silos, Thesis, University of Western, Australia, 2002

[36] J.M. Rotter, J.M.F.G. Holst, J.Y. Ooi, A.M. Sanad, Silo pressure predictions using discrete-element and finiteelement analyses, Philos. Trans. R. Soc. Lond. A (1998) $2685-2712$

Cite this article as: S. Kermiche, O. Boussaid, B. Redjel, A. Amirat, FEM investigation of concrete silos damaged and reinforced externally with CFRP, Mechanics \& Industry 18, 609 (2017) 